Juntendo Medical Journal

2018. 64 (Suppl 1), 34

\title{
The Medal Ratio of Countries at the Olympic Games and the Paralympic Games from a Socio-Economic Viewpoint
}

\author{
TADASHI WATARI*1), NORIO IDEGUCHI*2) \\ *1) Faculty of Health and Sport Science, Juntendo University, Chiba, Japan, \\ *2) Faculty of Acupuncture, Morionomiya University of Medical Sciences, Osaka, Japan
}

\begin{abstract}
Introduction: In the twenty-first century, the Olympic Games and the Paralympic Games are held by the same organising committee, and both events are covered simultaneously by the media. Under these conditions, it can be observed that the preparations for the Paralympics are delayed in comparison to those for the Olympics. Furthermore, the medal count of the Paralympic games is much lower than that of the Olympic games. Therefore, the purpose of this study is to illustrate medal standings of the Olympics and the Paralympics and to analyze socio-economic indicators to clarify the characteristics of each participating country.

Methods: The subjects of this study were 47 countries which have received the medals from the Olympic Games or the Paralympic Games. The data was collected from both events since the 2000 summer games and the 2002 winter games. In the analysis, we use some socio-economic indicators such as GDP, GDP per capita, population, political system, health and welfare system, military situation (peace and order situation), national curriculum, etc. Results and Conclusions: Here, we show a part of the results for the last two games. At the London Games, the number of medals in the Olympic Games was 962, and that of the Paralympic Games was 1,522. The ratio of the medals between the two games was 0.63 (Olympic per Paralympics) and the correlation coefficient was 0.669 $(\mathrm{p}<0.01)$ in countries which got medals from both events. Furthermore, at the Rio de Janeiro Games, the number of medals in the Olympic Games was 974, and in the Paralympic Games it was 1,597. The ratio of the medals of both games was 0.60 (Olympic per Paralympics), and the correlation coefficient was $0.552(\mathrm{p}<0.01)$. Therefore, a correlation is assumed between the Olympics and the Paralympics. At the same time, in many countries, the medal ratio shows a value smaller than 1 and the number of medals of the Paralympic Games is larger than that of the Olympic Games. However, in the case of Japan, the medal ratio at the London Games was 2.375. This was the highest among the OECD member countries. These show that the Japanese situation regarding sport is extremely biased toward the Olympic Games. At the London Games, it can be assumed that the medal ratio of each country has a roughly normal distribution. But the value of the ratio of Japan can be rejected by the Smirnov-Grubbs' test. On the other hand, at the Rio Games, the medal ratio of Japan improved to 1.70; still, the bias towards the Olympic Games has remained. These facts clearly show the attitude toward the Paralympic Games in Japan.
\end{abstract}

Key words: Olympic Games, Paralympic Games, Medal Index

Corresponding author: Tadashi Watari

Faculty of Health and Sports Science, Juntendo University

1-1 Hirakagakuendai, Inzai-shi, Chiba 270-1695, Japan

TEL: +81-473-90-1001 FAX: +81-476-98-1011 E-mail: t-watari@juntendo.ac.jp

〔Received Nov. 26, 2017〕〔Accepted Feb. 13, 2018〕

Copyright (C) 2018 The Juntendo Medical Society. This is an open access article distributed under the terms of Creative Commons Attribution License (CC BY), which permits unrestricted use, distribution, and reproduction in any medium, provided the original source is properly credited. doi: 10.14789/jmj.2018.64.JMJ18-P15 